\title{
Speed control of switched reluctance motor using genetic algorithm and ant colony based on optimizing PID controller
}

\author{
Hassan El-Sayed Ahmed Ibrahim ${ }^{1}$, Mohamed Said Sayed Ahmed ${ }^{2}$, and Khaled Mohamed Awad ${ }^{3, *}$ \\ ${ }^{1}$ Electrical Engineering and Computer Control Department at Arab Academy for Science, Technology and Maritime Transport, Cairo, \\ Egypt \\ ${ }^{2}$ Electrical Engineering and Control Department at the Military Academy, Cairo, Egypt \\ ${ }^{3}$ Instrumentation and control department at BAPETCO/SHELL J.V Petroleum Company, Cairo, Egypt
}

\begin{abstract}
Proportional-Integral-Derivative control is the most used kind of control which provides the simplest and most effective solution to different kinds of control engineering applications. But until now PID controller is poorly tuned in real life and online applications. While most of PID tuning is done manually. Switched reluctance motor (SRM) has highly nonlinear characteristics since the developed/produced torque of the motor has a nonlinear function on both phase current and rotor position. These nonlinearities of the SRM drives make the conventional PID (proportional + integral + Derivative) controller a poor choice for application where high dynamic performance is desired under all motor operating conditions. research paper comes up with two artificial and hybrid techniques involving Genetic Algorithm (GA) and Ant Colony Optimization (ACO). Those techniques where used to tune the PID parameters for the switched reluctance motor (SRM) and its performance were compared with the conventional method of "Ziegler Nichols. The results obtained reflects that, the use of those algorithms based controller improves the performance of the whole process in terms of a fast set point tracking and regulatory changes and also provides an optimum stability for the system itself with a minimum overshoot on the output signal.
\end{abstract}

\section{Introduction}

In this research, we show that the control of the switched reluctance motor (SRM) is apparently an easy task but in real world it is difficult to be achieved when using a simple PID controller due to its nonlinear characteristics $[1,15]$. So according to that, we use artificial intelligent techniques like Genetic Algorithm and Ant-Colony optimization to be able to achieve a robust steady speed performance under different load circumstances.

Also it has some good features, like high power density, high efficiency and no rotor windings. This is one of its major advantages. However, the SRM motor suffers from torque ripples and acoustic noises that prevent its use in high performance drives [14].

A Matlab-Simulink model for the speed control of a 3-phase switched reluctance motor carried out using different controllers. The Simulink models designed here are the traditional PID, Genetic-PID and Ant ColonyPID controllers which are designed separately and their performance results were compared together. The speed controller applied here is based on the traditional PID Controller and the other one is an artificial intelligent based controller like Genetic algorithm \& Ant Colony Controllers. A comprehensive review/research has been done for SRM machine modelling, simulation, analysis and control. The conventional controller design (i.e.
PID) is based on the mathematical model of the plant, which may often be unknown, ill-defined, nonlinear and complex. The PID controller has fixed gains and is certainly the most commonly used control algorithm nowadays. The main reason for using it until now is its relatively simple structure which can be easily understood and implemented in real world. The PID controller has traditionally been tuned empirically e.g. by the method described in Ziegler and Nichols. The controller gains once tuned for a given operating point for a specific plant or a system are only suitable for limited operating point changes and this is one of its disadvantages. Therefore, the use of the conventional PID controller does not meet the requirements of a robust \& steady speed performance. Various control strategies has been proposed for the speed control of the SRM, such as feedback linearization control, fuzzy logic control and neuro-fuzzy control. While GA and ACO techniques those are based on the behavioral pattern of a living being and are a new artificial methods introduced strongly to control the SRM motor. The objective of this research paper is to show that a 3-phase SRM motor using the conventional PID controller, its values can be obtained and optimized using the artificial techniques of

Corresponding author: eng.kha_Awad@hotmail.com 
GA and ACO, which gives better results with sudden load changes and system stability.

\section{Switched Reluctance Motor}

The switched reluctance motor has a passive rotor with a simple construction. While the solution of its mathematical model is relatively difficult due to its nonlinear behavior. The SRM is characterized by its geometrical Layout, the characteristic of the magnetic material and electrical parameters Switched reluctance motor (SRM) drives are of simple construction compared to the induction or synchronous motors. The structure of the motor is very simple that uses salient poles on both stator and rotor but only stator carries winding. The windings on the stator are of simple form. So this apparent simplicity of its design is not very accurate because its construction is simple but controlling the motor itself is difficult. SRM drives has some advantages as it has high efficiency, maximum operating speed, good performance of the motor in terms of torque/inertia ratio, according to that it can be used in variable speed applications with high speed. The performances of switched reluctance motor strongly depend on its applied control. Figure 1 shows the major parts of a switched reluctance motor drive.

There is three main parts identified as follows: the motor itself, the power electronic converter and the controller used. SRM construction consists of the following: There is a single converter per phase; a battery supplies the dc power to the converter. Its operation is simple: When the excitation is given to the stator windings, a force is created by rotor's magnetic reluctance that tries to align the rotor pole with its adjacent stator pole (Fully aligned) in order to maximize the inductance \& minimize reluctance of the excited coils. In order to preserve the correct sequence of rotation, the windings of stator pole switches in a sequential order with the help of electronic control system so that the magnetic field of rotor pole was led by the stator pole, pulling towards it production of torque is independent of the direction of current which in-turn reduce the number of switches per phase.

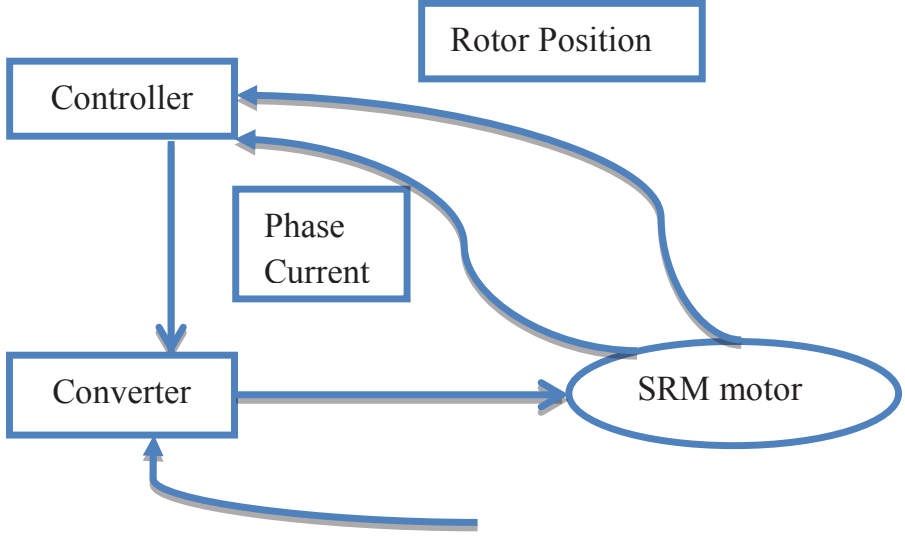

Vdc battery input

Fig.1. Switched Reluctance Drives System Components

\section{SRM Block Diagram}

The position of rotor is sensed by the rotor position sensor and it provides its corresponding output to the error detector. Error detector compares reference speed given in RPM and the actual speed feedback from the motor itself to generate an error signal which is given to the controller block. The controller (PID or GA-PID or ACO-PID) gives control signal to the converter according to the error signal value. The speed of the motor is controlled by the converter through proper excitation of their corresponding windings.

Given Reference Speed

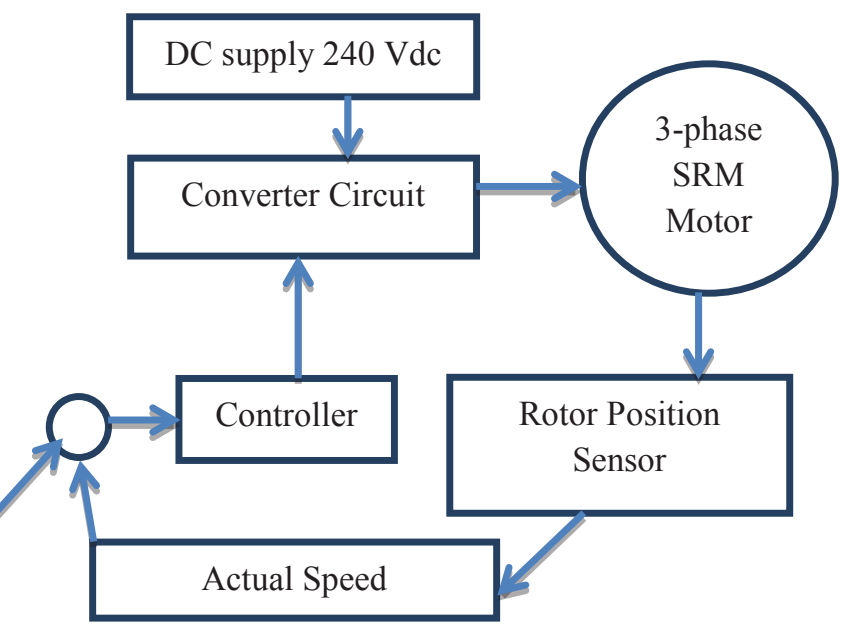

Fig.2. Block Diagram of SRM Speed Control 


\section{Genetic Algorithms}

Genetic Algorithms were invented to try to mimic some of the processes observed with living being [3-5]. The idea with GA is to use the power of natural living ability for evolution to solve hard and very complicated Engineering optimization problems [13]. GA's process starts with no knowledge at all for the correct and accurate solution and depends entirely on responses it receives from the surrounding environment and its internal evolution operators such as reproduction, $\underline{\text { crossover }}$ and mutation to get to the best available solution.

The application of these three basic operations allows the creation of new and better individuals, which may be better than their old parents. This algorithm is repeated for many generations and at the end we stops when we reaches for individuals that represent the optimum solution to the problem or we stop at certain number of iterations we initially stated.GA starts with an initial and random chromosome $\&$ checks its fitness value. The fittest chromosome are taken as parents for further reproduction also to be crossed over \& mutated again. The offspring or their children are checked for the fitness value \& depending on it. We can decide either to be taken again or to be neglected from the population [7, $16,17]$. Genetics father is "John Holland" who invented this technique in the early 1970's [6]. GA's is an adaptive artificial search technique based on the evolutionary ideas of natural selection [7]. In order to use the "GA's" there are two important aspects to follow: chromosome coding and defining the evaluation criteria. Although it appears as a randomized process, GA's is not a completely random process. Instead it develops some historical information to direct the search into the region of better performance within the search space it has. The Basic techniques of the GA's are designed to simulate processes with natural living being which is necessary for evolution as found on the block diagram on Figure 3. Especially those who follows the principles of Charles Darwin "survival of the fittest" Since in nature, competition among individual's results in the fittest individuals dominating over the weaker ones and this is observed and proved its existence in history. GA's can give robust $\&$ adaptive response for a system with nonlinearity, parameter variation and load disturbance effect [3-5].

GA's is better than traditional techniques and more robust to sudden load changes and is a very adaptive technique. Unlike old AI systems, they do not break easily if the input changes or noise applied suddenly. Also in searching a large state-space, GA's may offer significant benefits over the typical search of optimization artificial techniques.

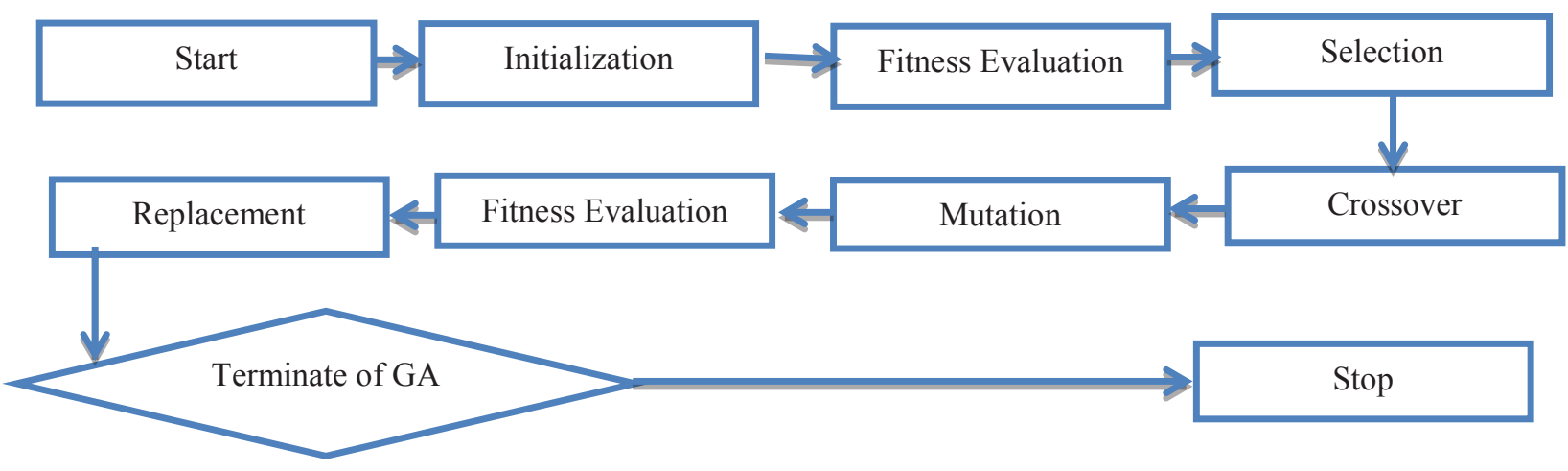

Fig.3. Block Diagram for GA Sequence

\section{Ant Colony Optimization}

Marco Dorigo and some of his colleagues invented the first ACO concept in the early 90's [8, 9, 10]. The development of these algorithms was inspired by the observation of ant colonies in nature. Ants are social insects with an ability to organize their food obtaining process very accurately. They live in colonies (groups) and their behavior is governed by the goal of colony survival rather than being focused on the survival of individuals. Ant algorithms are adaptive and robust to any complicated engineering problem. The behavior that provided the inspiration for ACO is the ants "foraging behavior" and in particular, how ants can find the shortest path between food sources and their nest (Home). The main advantages of artificial ants are taken from their natural model. Which are (1) artificial ants exist in colonies of cooperating individuals; (2) they communicate indirectly by depositing pheromone on their way to any expected food sources $[11,12](3)$ they use a sequence of local moves to find the shortest path from a starting position which is completely random, to a destination point they apply a stochastic decision policy using local information only to find the best solution. 
When searching for food supplies (Sources), ants initially searches the surrounding area or explores it which is near its nest. This is in completely random directions. While moving it leaves a small amount of pheromones behind it on the ground. This is in order for the other ants to smell it during this trip of finding food sources. While other ants search for food it chooses its way in a probability which is according to the amount of pheromones it finds. As soon as an ant finds a food source, it tries to know the quantity and the quality of these sources of food and carries some of it back to its home base. During the return trip the quantity of

a) All Ants are in their home (Nest) there is no pheromone in the environment at all.
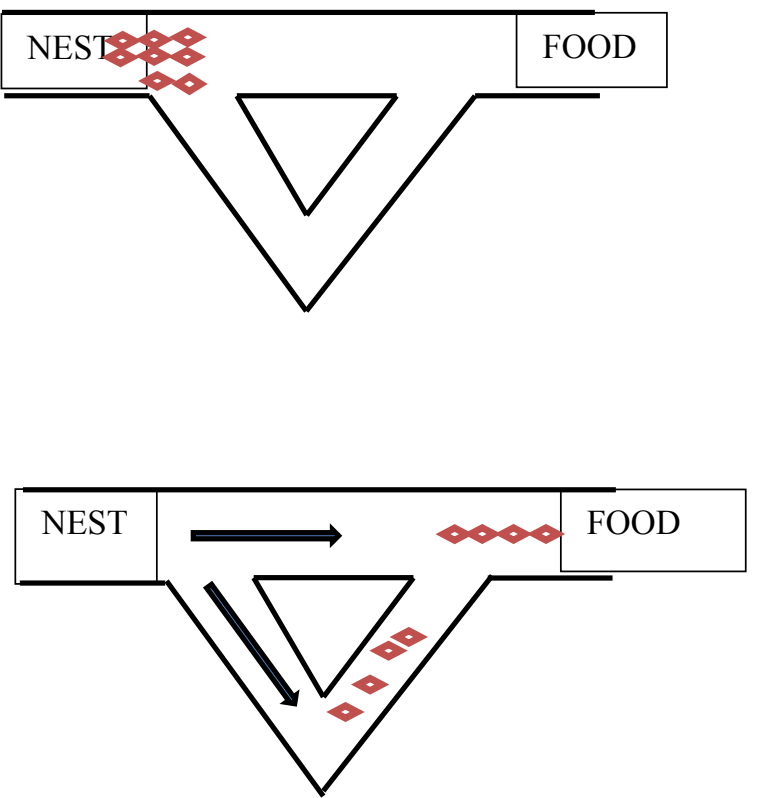

c) The Ants that have taken the shorter path arrived earlier to the food source. While during the return cycle the probability of taking the same path again is higher

Fig. 4. Experimental setting that demonstrate the Shortest Path Finding Capability of Ant Colonies, between the ants nest and the only food source exist with two paths of different length pheromone it was left over during the trip is evaluated again to try to know the shortest route to its nest. When it reaches its nest other ants will go on the same route to the food source which contains actual food as illustrated on figure 4 .

It has been shown that, this kind of communications is an indirect one which is built in every ant to get to its nest as soon as possible and in an organized manner also it is called "stigmergy effect" which enables them to find the shortest path between their home base and expected food source. b) The Foraging or a trip to find food source starts approximately $50 \%$ of ants take the one path and the other $50 \%$ take another path to the food source.
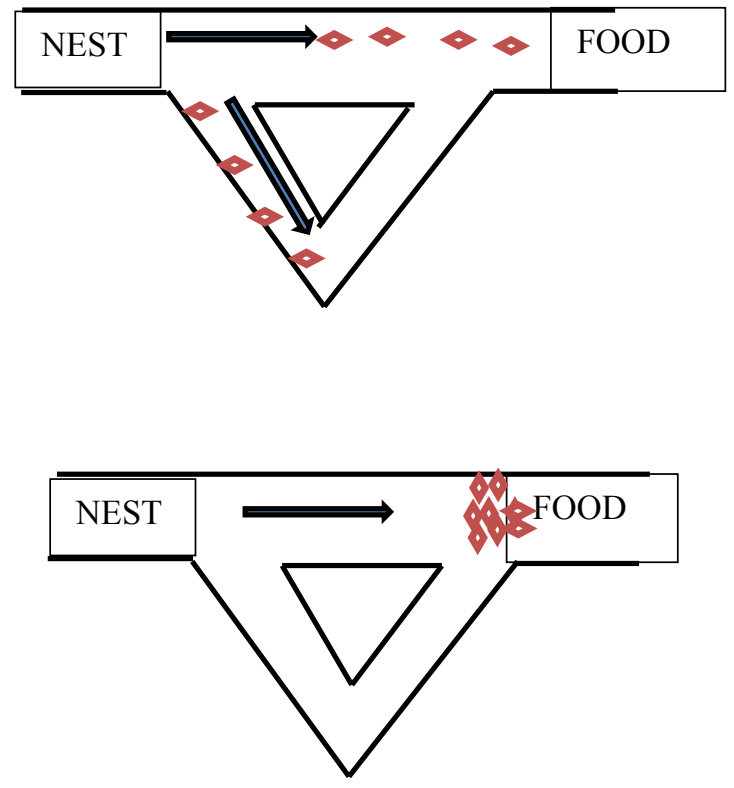

d) The pheromone trail on the short path receives, in probability a stronger pheromone scent and the probability to take this path grows again stronger. Finally due to the evaporation of the pheromone on the longer path, whole colony will use the shorter path 


\section{Experimental Setup of the SRM Drive Using Matlab-Simulink}

The experimental setup is shown on Figures 5, 6. This shows the PID controller optimized by GA's also the same PID controller optimized by ACO technique. We start the simulation by using a 3-phase 60KW SRM motor which is used on this research paper with motor features as found on table 1 .

Also it is the same built-in Matlab motor model. Tables 2 and 3 shows the GA's and ACO controller's parameters used after several trials. the response of $\mathrm{Kp}$, $\mathrm{Ki}$ and $\mathrm{Kd}$ parameters are summarized on table 4 which shows that using the proportional controller "Kp" will have the effect of reducing rise time of the output signal and will reduce the steady state error while the integral controller "Ki" will have the effect of eliminating the steady state error have the effect of eliminating the steady state error produced by the "Kp" parameter but will have the worst transient response on any system.

While the derivative controller "Kd" will have the effect of increasing the stability of the system, reducing the overall overshoot and improves the transient response of the system. Several simulations were carried out for controlling motor's speed with a different load torque disturbances to explore the effectiveness of the proposed controller's robustness in comparison with the conventional old PID controller.

The results were obtained for cases such as step variable (Input) speed of ranges starts from "1000-1500 RPM" which is our maximum RPM for such motor and under variable load torque "Nm".

Table 1

Matlab built-in Motor Features

\begin{tabular}{|c|l|c|}
\hline Item & \multicolumn{1}{|c|}{ Features Description } & Value \\
\hline 1 & Rotor Pole number "Nr" & 6 \\
\hline 2 & Stator Pole Number "Ns" & 8 \\
\hline 3 & Turn on angle & 40 degree \\
\hline 4 & Turn off angle & 75 degree \\
\hline 5 & Number of Phase & 3 \\
\hline 6 & Power in (KW) & 60 \\
\hline 7 & $\begin{array}{l}\text { Maximum (Reference) speed } \\
\text { (RPM) }\end{array}$ & 1500 \\
\hline 8 & Stator Resistance (Ohm) & 0.05 \\
\hline 9 & Inertia (Kg.m.m) & 0.05 \\
\hline 10 & Friction (N.m.s) & 0.02 \\
\hline 11 & Source Voltage (Vdc) & 240 \\
\hline
\end{tabular}

Table 2

\section{Genetic Algorithm Parameters}

\begin{tabular}{|c|l|c|}
\hline Item & \multicolumn{1}{|c|}{ Description } & values \\
\hline 1 & $\begin{array}{l}\text { Proportional gain limits } \\
\text { Kp }\end{array}$ & Ranges [0-100] \\
\hline 2 & Integral gain limits Ki & Ranges [0-100] \\
\hline 3 & $\begin{array}{l}\text { Derivative gain limits } \\
\text { Kd }\end{array}$ & Ranges [0-100] \\
\hline 4 & Population type & Double vector \\
\hline 5 & Population size & Uniform \\
\hline 6 & Creation Function & 0.1 \\
\hline 7 & Mutation rate & Uniform \\
\hline 8 & Mutation Function & Uniform \\
\hline 9 & $\begin{array}{l}\text { Selection method } \\
\text { "Function" }\end{array}$ & Arithmetic \\
\hline 10 & Crossover type & \\
\hline
\end{tabular}

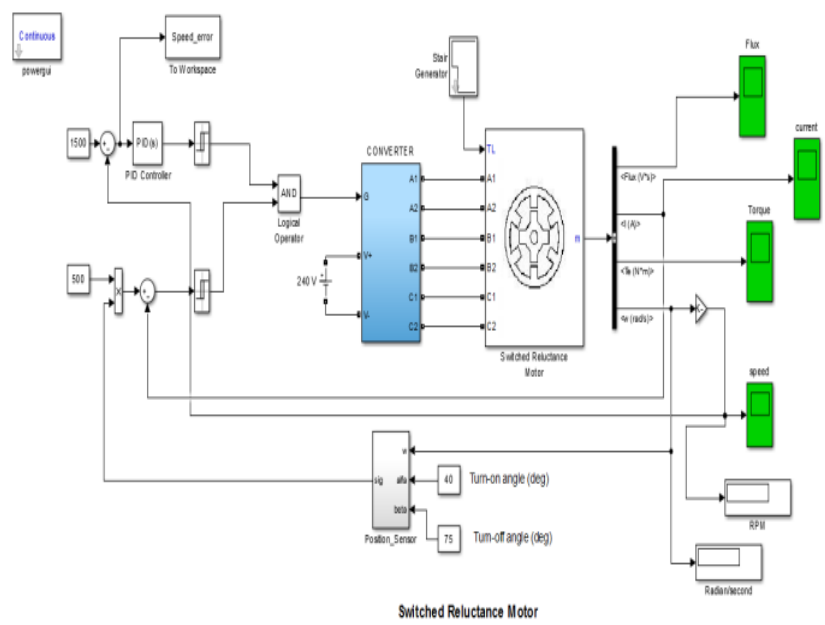

Fig.5. SRM motor speed control with GA-PID Controller.

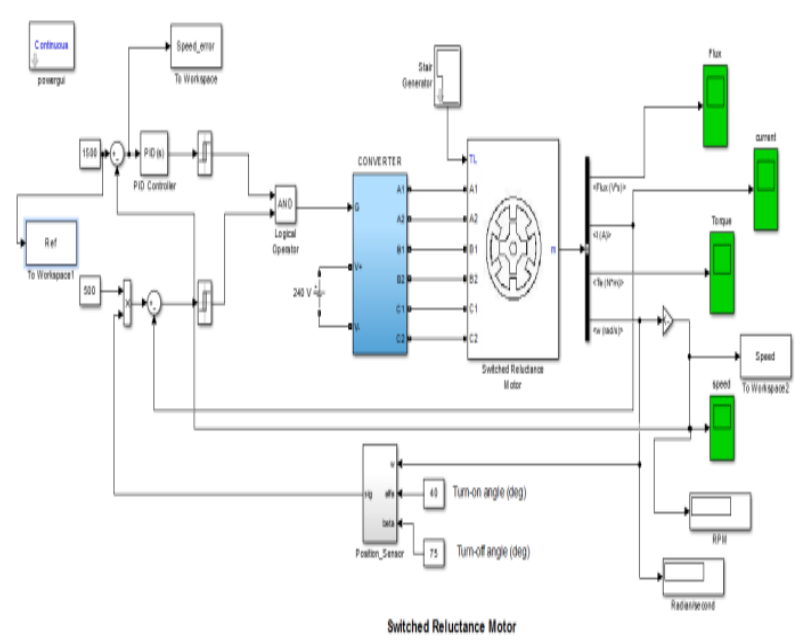

Fig.6. SRM motor speed control with ACO-PID controller 
Table 3

Ant Colony Parameters

\begin{tabular}{|c|l|c|}
\hline Item & \multicolumn{1}{|c|}{ Description } & values \\
\hline 1 & Number of Iterations & 100 \\
\hline 2 & Number of Ants & 300 \\
\hline 3 & Alpha & 0.8 \\
\hline 4 & Beta & 0.2 \\
\hline 5 & Evaporation Rate & 0.7 \\
\hline 6 & Number of Parameters & 3 \\
\hline 7 & Lower\& upper limits & {$[000] \&$} \\
& & {$[111]$} \\
\hline
\end{tabular}

Table 4

Response of $\mathbf{K}_{\mathrm{p}}$, $\mathbf{K}_{\mathrm{i}}$ and $\mathbf{K}_{\mathbf{d}}$

\begin{tabular}{|c|c|c|}
\hline Item & $\mathrm{K}_{\mathrm{p}}$ & $\mathrm{K}_{\mathrm{i}}$ \\
\hline Rise time & Decrease & $\begin{array}{c}\text { Small } \\
\text { change }\end{array}$ \\
\hline Overshoot & Increase & $\begin{array}{c}\text { Decreas } \\
\mathrm{e}\end{array}$ \\
\hline Settling time & Small change & $\begin{array}{c}\text { Increas } \\
\mathrm{e}\end{array}$ \\
\hline $\begin{array}{c}\text { Steady state } \\
\text { error }\end{array}$ & Decrease & $\begin{array}{c}\text { Elimina } \\
\text { te }\end{array}$ \\
\hline Item & $\mathrm{K}_{\mathrm{p}}$ & $\mathrm{K}_{\mathrm{i}}$ \\
\hline
\end{tabular}

\section{Simulation Results}

To explore the effectiveness of the proposed techniques, a Matlab-Simulink computer simulation has been carried out for the different proposed controllers. The conventional PID, GA-PID and ACO-PID controllers system [i.e. the maximum torque obtained, rotor's position, reference and actual speed values, speed error signal and change in the error signal, input values of torque, produced flux current] can be observed.

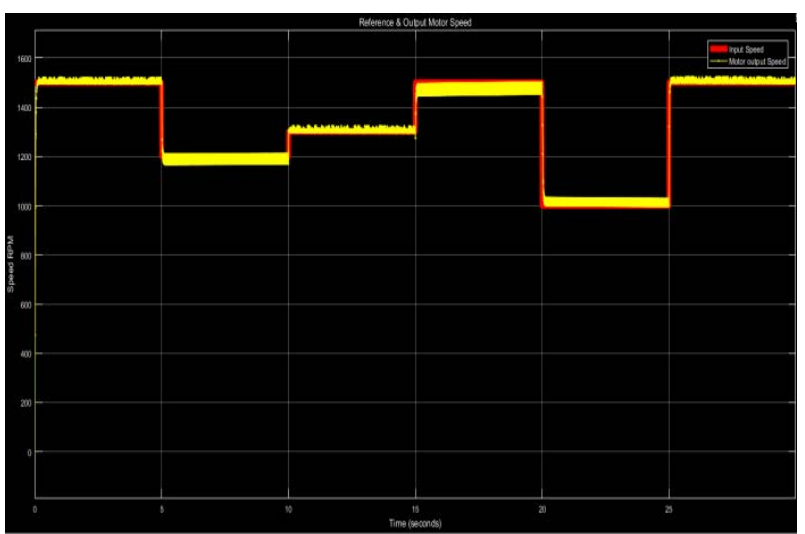

Fig.7. shows the variable step input (Speed) and the motor actual output speed after using Conventional PID controller.

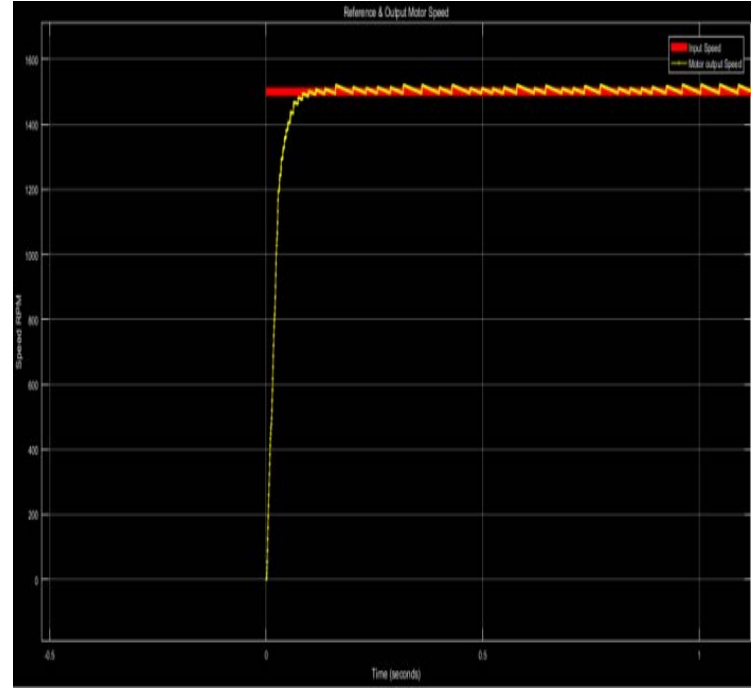

Fig.8. shows the delay on the output (Zoomed in) of the motor with reference step input when using conventional PID controller.

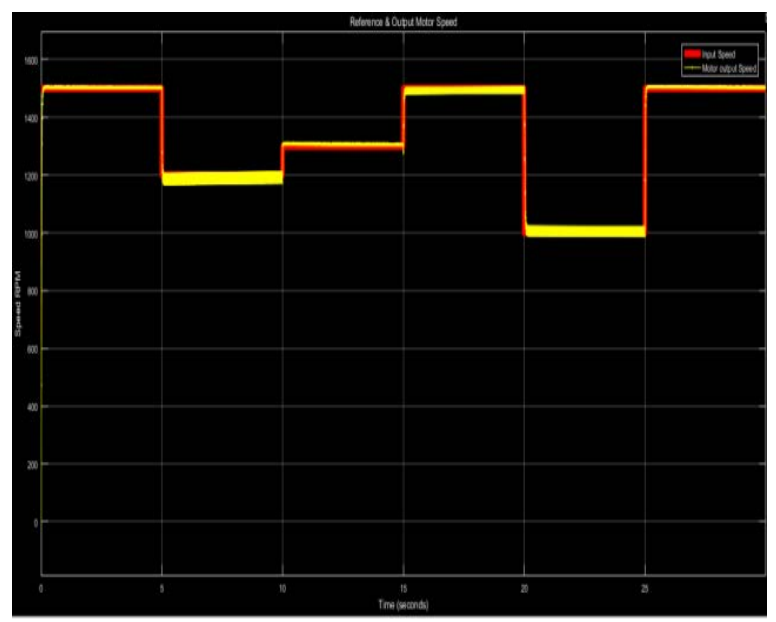

Fig.9. shows the variable step input (Speed) and the motor actual output speed after using the new artificial Genetic algorithm Technique. 


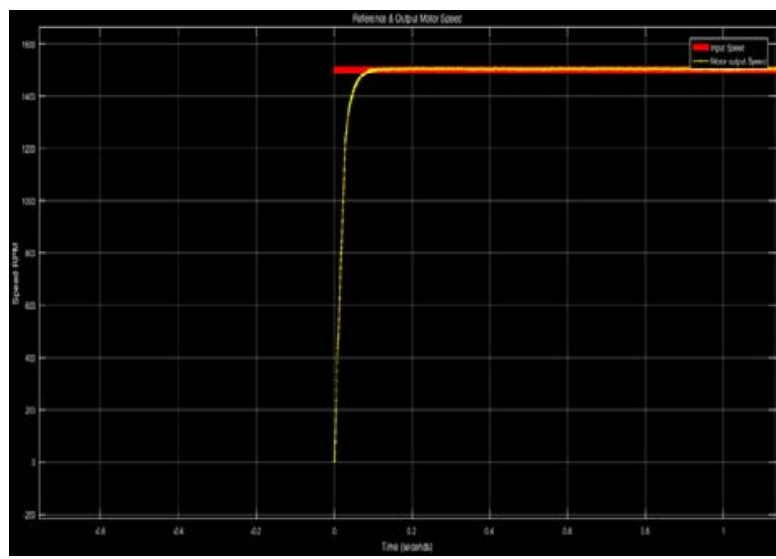

Fig.10. Shows the delay on the output (Zoomed in) of the motor with reference step input when using the Genetic algorithm

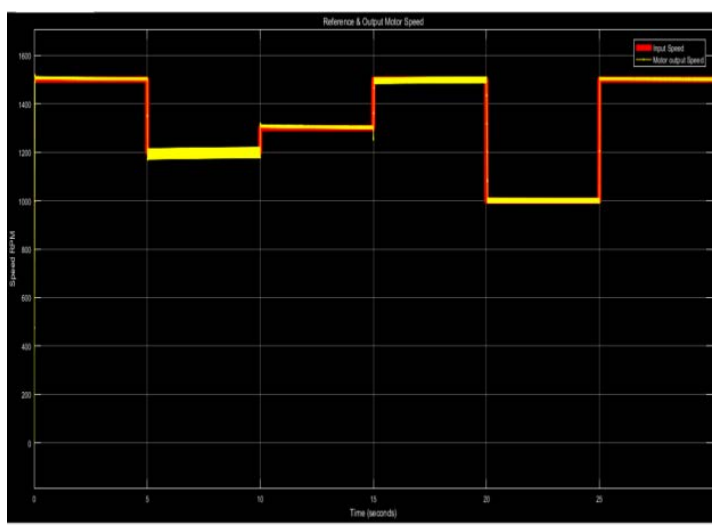

Fig.11. Shows the variable step input (Speed) and the motor actual output speed after using the Ant Colony technique.

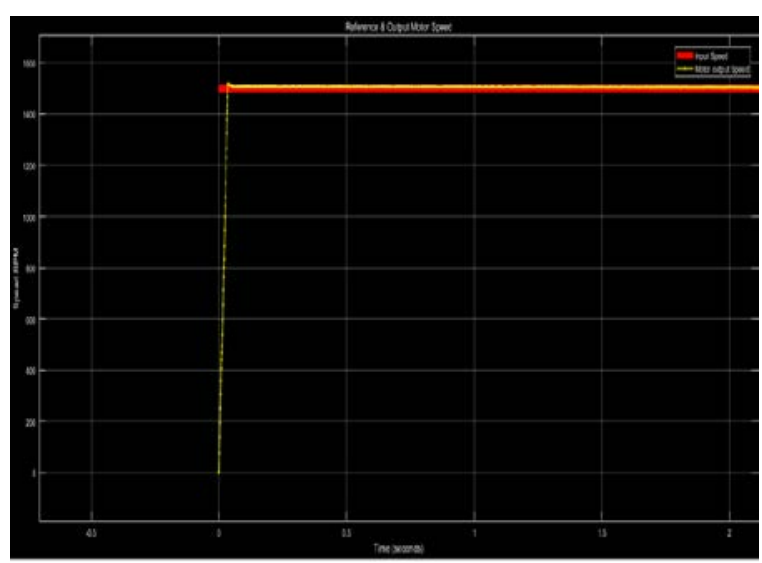

Fig.12. Shows the delay on the output of the motor with reference step input when using the Ant Colony technique

\section{Future Works}

The ACO and GA can be modified for future enhancement such that a new and updated research could and can be focused on each technique disadvantages in order to produce better solution by improving the effectiveness of getting the best solution and reducing its limitations. Research work has been carried out to get the maximum and optimal values for PID controller parameters automatically using GA and ACO artificial optimization techniques as found on figures 9,10 , 11 and 12. Simulation results demonstrate that the tuning methods proposed and used as found on both figures 10 and 12 have a better control performance compared with the conventional ones as found on figure 8 also they have a better steady state response, rise time, settling time, overshoot and a robust control with variable loads as found on table 5.

Table 5

Comparison between the conventional control method (PID) and Heuristic Intelligent artificial methods (GA \& ACO)

\begin{tabular}{|c|c|c|c|c|c|c|}
\hline $\begin{array}{c}\text { Tuning } \\
\text { Method }\end{array}$ & \multicolumn{3}{|c|}{ PID Parameters } & \multicolumn{2}{c|}{ Dynamic Performance Specifications } \\
\hline \multirow{2}{*}{$Z \mathrm{~N}$} & $\begin{array}{c}\text { Kp } \\
\text { Proportional } \\
\text { gain }\end{array}$ & $\begin{array}{c}\text { Ki } \\
\text { Integral } \\
\text { gain }\end{array}$ & $\begin{array}{c}\text { Kd } \\
\text { Derivative } \\
\text { gain }\end{array}$ & $\begin{array}{c}\text { Tr } \\
\text { Rise time }\end{array}$ & $\begin{array}{c}\text { Ts } \\
\text { Settling } \\
\text { time }\end{array}$ & $\begin{array}{c}\text { Mp } \\
\text { Peak } \\
\text { overshoot }\end{array}$ \\
\cline { 2 - 7 } & 0.95 & 0.05 & 0.01 & $0.070 \mathrm{sec}$ & $0.10 \mathrm{sec}$ & $1.53 \%$ \\
\hline GA & 282.9 & 26 & 2.346 & $0.060 \mathrm{Sec}$ & $0.080 \mathrm{Sec}$ & $0.53 \%$ \\
\hline ACO & 268.8579 & 65.86439 & 0.01 & $0.036 \mathrm{Sec}$ & $0.037 \mathrm{sec}$ & $1.2 \%$ \\
\hline
\end{tabular}




\section{REFERENCES}

1. Krishnan, R., Switched Reluctance Motor Drives, CRC Press, Boca Raton, Florida, (2001).

2. Ziegler, J. G., and Nichols, N. B., "Optimum settings for automatic controllers," Trans. ASME, Vol. 64, pp. 759-768, (1942).

3. Fleming, P. J., and Purshouse, R. C., "Evolutionary algorithms in control system engineering: A survey," Control Eng. Practice, Vol. 10, pp. 1223-1241,(2002).

4. Krohling, R. A., and Rey, J. P., "Design of optimal disturbance rejection PID controllers using genetic algorithms," IEEE Trans. Evol. Comput, Vol. 5, pp. 78-82, (February 2001).

5. Karr, C., and Gentry, E., "Fuzzy control of ph. using genetic algorithms," IEEE Trans. Fuzzy Syst., Vol.1, No. 1, pp. 46-53, (1993).

6. Goldberg, D. E., Genetic Algorithms in Search, Optimization and Machine Learning, Addison- Wesley Publishing Company, Boston, Mass., (1989).

7. Zhu Supeng \& Fu Wenxing Yang Jun Luo Jianjun "Applying Genetic Algorithm to Optimization Parameters of Missile Control System" 978-0-7695-3745-0/092009 DOI 10.1109/HIS.2009.297 IEEE (2009) Ninth International Conference on Hybrid Intelligent Systems.

8. Dorigo M, Stützle T. Ant Colony optimization. Cambridge, MA: MIT Press; (2004).

9. Dorigo M, Optimization, learning and natural algorithms. PhD thesis, Dipartimento di
Elettronica, Politecnico di Milano, Italy, (1992) [in Italian].

10. Dorigo M, Blum C. Ant colony optimization theory: A survey. Theoret Comput Sci (2005); 344(2-3):243-78.

11. Deneubourg J-L, Aron S, Goss S, Pasteels JM. The self-organizing exploratory pattern of the Argentine ant. J Insect Behavior (1990); 3:159-68.

12. Grassé P-P. La reconstruction du nid et les coordinations inter-individuelles chez bellicositermes natalensis et cubitermes sp. La théorie de la stigmergie: Essai d'interprétation des termites constructeurs. Insectes Sociaux (1959):6 41-81.

13. Ian Griffin, Jennifer Bruton "On-Line PID controller tuning using genetic algorithm". Available at: www. eeng.dcu.ie/ brutonj/Reports/IGriffin_MEng_ 03.pdf.

14. JIn-Woo Ahn (2011). Switched Reluctance Motor, Torque Control, Prof. Moulay Tahar Lamchich (Ed.), ISBN: 978-953-307-428-3, InTech, Available from: http://www.intechopen.com/books/torquecontrol/switchedreluctance- Motor

15. V. Vasan Prabhu, K. S. Mahesh, C. Renuka,"Simulation of Switched Reluctance Machine for Linear and Nonlinear Model", International Conference on Computer, Communication and Electrical TechnologyICCCET (2011), 18th \& 19th March, 2011,pp.333-339 